\title{
Future Scenario Settings for Supply Chains
}

\author{
Saskia Sardesai, Markus Stute, Rosanna Fornasiero, Dimitra Kalaitzi, \\ Ana Cristina Barros, Cemre Multu, and Victoria Muerza
}

\begin{abstract}
Trends and future developments make it necessary to discuss the future, but it is their bundling that forms a future scenario. This chapter describes six identified and verified macro-scenarios for future industry specific settings, which are shaped by various socio-economic, political, technological and environmental future developments. The description of each macro-scenario allows conclusions to be
\end{abstract}

\author{
S. Sardesai $(\varangle) \cdot$ M. Stute \\ Fraunhofer Institute for Material Flow and Logistics, Joseph-von-Fraunhofer-Str. 2-4, 44137 \\ Dortmund, Germany \\ e-mail: saskia.sardesai@iml.fraunhofer.de \\ R. Fornasiero \\ Institute of Intelligent Industrial Technologies and Systems for Advanced Manufacturing, \\ National Council of Research (STIIMA-CNR), Via Alfonso Corti, 12, 20133 Milan, Italy \\ e-mail: rosanna.fornasiero@cnr.it \\ Institute of Electronics, Computer and Telecommunication Engineering, National Council of \\ Research (IEIIT-CNR), c/o Università di Padova, via Gradenigo 6/B, 35131 Padova, Italy \\ D. Kalaitzi \\ Aston Logistics \& Systems Institute, School of Engineering and Applied Science, Aston \\ University, Aston Triangle, Birmingham B4 7ET, UK \\ e-mail: d.kalaitzi3@aston.ac.uk
}
A. C. Barros
INESCT TEC Institute for Systems and Computer Engineering, Technology and Science, Campus da FEUP, Rua Dr. Roberto Frias, 4200-465 Porto, Portugal
e-mail: ana.c.barros@inesctec.pt
C. Multu
PNO CONSULTANT, Avenue de la Joyeuse Entrée 1, 1040 Brussels, Belgium
e-mail: cemremultu@gmail.com

\author{
V. Muerza \\ MIT International Logistics Program, Zaragoza Logistics Center, C/Bari 55, Edificio Náyade 5 \\ (PLAZA) 50197, Saragossa, Spain \\ e-mail: vmuerza@unizar.es
}

University of Zaragoza, Quantitative Methods for Business and Economy, Gran Vía 2, 50005, Saragossa, Spain 
drawn on supply chain developments such as circular aspects, trade impacts or necessary supply chain structures. Each future scenario is set in a conceptual framework that provides the context and meaning of possible futures and enables companies to prepare and adjust their strategies accordingly.

Keywords Scenario description - Narratives $\cdot$ Future supply chains $\cdot$ Logistics • Scenario analysis

\section{Introduction to a Scenario Description}

A scenario description represents a possible future development in narrative form which denotes its main characteristics (Meinert 2014). It portrays causal relationships that explain how, from the vantage point of the present, a particular future in a certain story setting has been derived. In so doing, a scenario has to be distinguished from a prognosis as scenarios indicate different possible states of the future without defining just one single status. Scenarios outline aspects of the future for public (Wilkinson and Eidinow 2008) and private institutions or private interests (Amer et al. 2013). Thus, the generated scenarios help organisations to prepare for eventualities and potential circumstances and to ensure innovative and flexible development (Amer et al. 2013).

The creation of narrative descriptions conveys the content of the diverse future developments within a scenario. The description exposes all the progressive as well as the regressive future projections that are integrated while at the same time characterising the main features of each scenario. This enables a common understanding and promotes scenario communication. It furthermore displays that diverse sets of projections can lead to unexpected future outcomes. Discussants can draw their conclusions for each scenario description. The extraction of the main characteristics of each scenario enables the future to be conveyed in such a way that it is differentiated and rich in contrasts (Meinert 2014).

Figure 1 shows an exemplary set of scenarios from Meinert (2014). The example shows scenarios represented within a picture to explain the content and the overall development of the scenarios. Each picture highlights the relevant and differentiating settings within the respective scenario.

However, scenarios can be described not only by means of a picture, but also in the form of a narrative. In both cases it is important that a scenario description assists the user and the audience with their explanations. In this manner, conclusions can be drawn on how to prepare for, or even influence the different scenario alternatives identified in the scenario-building process. Weather scenarios as shown in Fig. 2 show a simple example for describing scenarios and the resulting strategies on how to approach the respective scenario in case it occurs. 


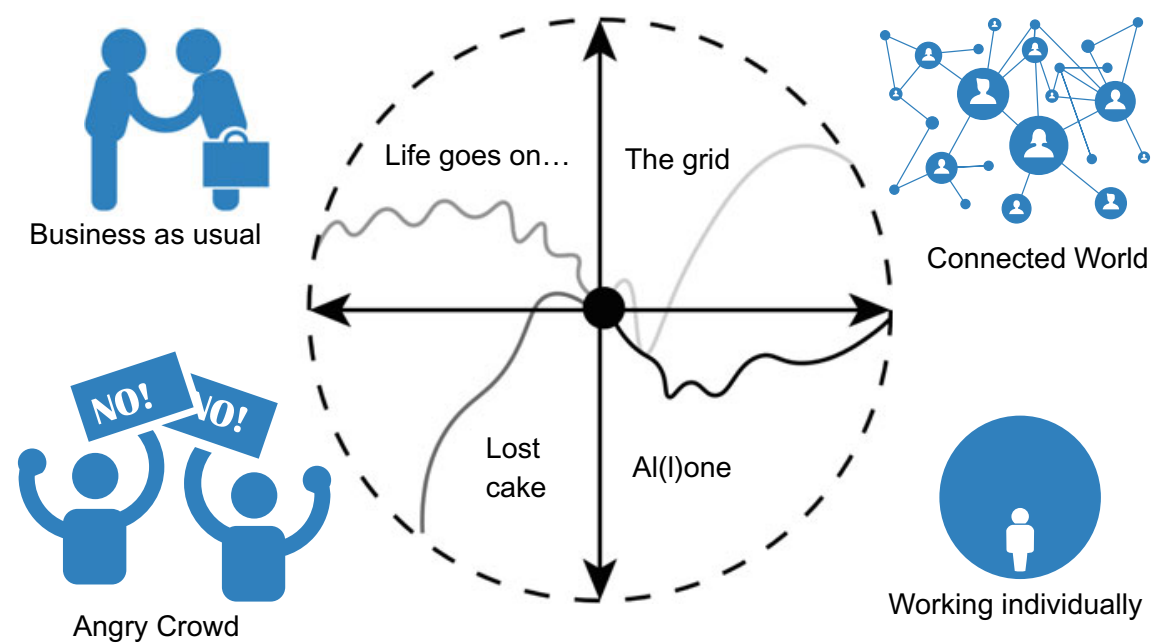

Fig. 1 Exemplary scenario naming and picture creation (adapted from Meinert 2014)

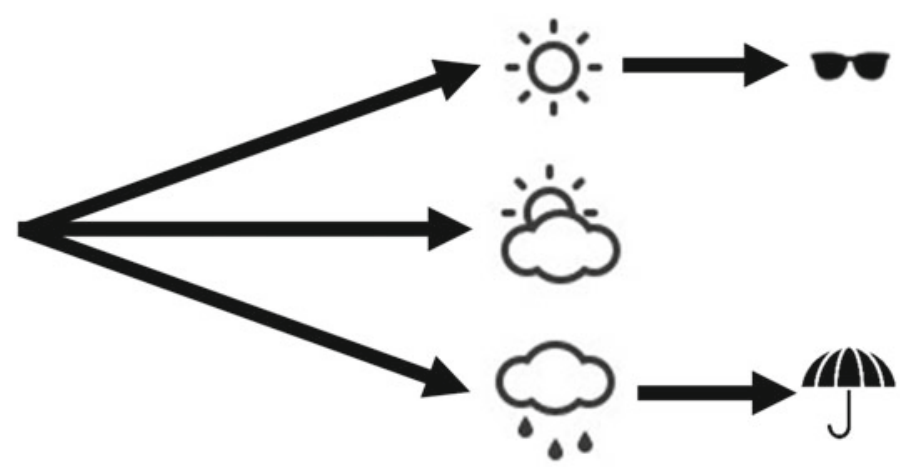

Fig. 2 Description of future projections based on future scenarios

\section{Macro-Scenarios for Future Supply Chains}

As scenario descriptions exemplify the relationship between the future projections, they serve to visualise each scenario, thus providing a common understanding. To generate this common understanding, each future projection within a scenario has been discussed in detail within an expert community. Different viewpoints have been considered (1) along with the interrelation between the future projections and (2) with regard to their impact on supply chains.

The result of these discussions are consolidated below and form six heterogeneous macro-scenarios. The description of each macro-scenario reveals the circumstances and surroundings future supply chains have to deal with by 2030 (based on 
results achieved in Sardesai et al. 2020). Each macro-scenario details its inherent future projections and their corresponding challenges with respect to supply chain management.

All macro-scenarios contain an explanation of their main characteristics and a description of the respective scenario settings. The description concludes with a table containing the most relevant projections for each PESTLE dimension (PESTLE_-political, economic, social, technological, legal, and ecological). The possible impacts on the supply chain structure and processes complement the scenario setting.

The following scenario descriptions are arranged according to the similarity of their overall development and their projections. The narratives start with a scenario that outline an overall progressive development, aSPIRANT, and finalise with a scenario with rather stagnating and retrogressive developments, which has been named ENDANGEr.

\section{1 “aSPIRANT”-Strong PartnershIp enables homogeneous fRameworks Allowing a sustainable aNd Technological Development}

\section{aSPIRANT-General setting}

aSPIRANT represents a rather positive view of future developments in all PESTLE dimensions. This scenario particularly entails the following aspects:

- Stable political and economic environment supports technological developments

- Sustainable and prosperous societies in EU that lead to social, technical and economic development

- Social balance is influenced by social media communities

- Global enterprises have widely implemented digital technologies and the tech start-ups are the economic winners.

A stable political and economic environment within the EU and its neighbouring countries characterises this scenario. Common agreements allow for coordinated rules and regulations that are valuable in economic and trading risk situations such as pandemics and natural disasters. Free trade agreements involving the EU and other economic unions support and facilitate the exchange of goods. The EU remains strong in exports and intensifies the role as a net investor in the world. As the political setting allows quick adaptations to regulations, there are clear regulations for handling data, thus creating transparency and IP-security. In addition, the fast and widespread progress of digitalisation supports the digital economy. The advancements of collaborative platforms make it easy to share and utilize resources. New digital business models are emerging in many different sectors. Big companies are the first movers as they have the resources to invest in developing technologies, followed by the tech start-ups that complement the industrial sectors with new services such 
as Fintech Services, and upcoming platform strategies. These new services innovate complete industrial sectors.

The political and economic setting supports technological developments. Emerging technologies such as advancements in artificial intelligence (AI) assist humans by undertaking autonomous planning and handling tasks. White-collar tasks change from actual decision-making to the supervision of AI-based decisionmaking systems. Increased exploitation of these technologies leads to a highly automated and autonomous environment. Suppliers of disruptive technologies experience exponential growth rates and existing technologies improve quickly and continuously.

Social networks strongly influence consumer behaviour, thus, companies have to adapt quickly on a large scale. Residents of the EU are more ecologically aware and pay attention to the origin of products as well as their recycling potential. This mindset leads inter alia to a preference for living in the suburbs. Fast transportation and innovation in the mobility sector support this lifestyle development, and hence, those developments strongly influence the economy. Since fossil fuels are depleting as time goes by, renewable electricity generation, transmission and distributed energy resource systems become even more relevant. At the same time, new power grid solutions and grid transformations overcome technological limitations and create a smart grid environment with distributed energy generation and powerful storage systems. Table 1 comprises the individual future projections for the aSPIRANT scenario.

Table 1 Elements of the aSPIRANT scenario

IIII Political concord in EU; widespread free trade; stable alliances

AS and EU as global trade leaders; digital platform economics; techgiants dominate financial sector; globalised companies benefit

Sustainable consumer behaviour; social balance; adjusted labour market; living in smart regions

Digitalization, Industry 4.0 and "green systems" far advanced; predominantly large enterprises push disruptive developments

§ Legislative keeps pace with technological development

Climate protection successful; resource wastage curbed 


\section{aSPIRANT—Effects on supply chain}

Regarding supply chain structure, harmonious political and economic development provides good conditions for strategic agreements across several states. At the same time, the fast technological development as well as the development of new production technologies affect the structure of supply chains. New business models are required, firstly to adapt to advances in the digitalisation and platform economy and secondly to allow for ecological development in terms of circular economy. Specifically, more agile and circular supply chain structures are required to manage the product life cycle in a circular manner, paying attention to different types and quantities of waste. Product design needs to consider this circularity of feedstock along with its supply chain management. In addition, frequent adaptations to the supply chain structure are needed to support the increasing demand for individualised products and to adapt to technological innovations.

In terms of processes, the political harmony combined with contented unions result in smooth and fast cross-border supply chains. With regard to digitalisation and the use of platform strategies, new digital processes are required to respond to the technology enabling faster and secured information flows. New services and financial payment options enable the implementation of supply chain finance (SCF) methods. Digitalisation provides algorithms that plan supply chains holistically and embrace SCF concepts. Along with the fast legal changes within this scenario, a revision of the supply chain processes is frequently required to fulfil the new and rapidly advancing laws. The common agreements and cooperative approach within the European Union enable fast recovery from natural disasters and pandemic events by supporting the fast ramp up of supply chain capacities and structures. In terms of resources, the advancements in digitalisation and new process technologies necessitate a significant effort by research and development (R\&D). In addition, new employment or technological settings are required to deal with recycling and reusing processes across the globe to support the envisaged innovations successfully.

\section{2 "PrOCEEDIng"-POlitical CohErEnce, Disruptive technologies and Individualised consumerism facilitate an innovative business development}

\section{PrOCEEDIng-General setting}

The PrOCEEDIng scenario provides positive and harmonious overall development and embraces the following main developments:

- Stable political and economic environment with prospering medium sized businesses and start-ups which can adapt well to local markets and enable climate protection

- Customers act responsibly, but with a distinct demand for individualisation and living in smart megacities 
- Social, technical and economic developments are progressing in parallel and set a homogenous framework in a highly digitised world.

Overall, PrOCEEDIng describes a very harmonious picture of the future with a stable political and economic environment. As political and economic settings allow for quick adaptations to legal regulations, new technological developments rise significantly. Start-ups and SMEs take advantage of this ideal setting by focusing on niche markets and lean organisational structures. In addition, digitalisation is evenly integrated into the business environment and permeates all aspects of society. This empowers advancements in autonomous planning and new emerging technologies assist humans in handling tasks at work.

The technological developments enable platform economies to rise and there is a major trend towards a sharing economy. People take advantage of the numerous offers of a sharing economy both in business to consumer (B2C) and consumer to consumer (C2C) approaches. Further collaborative platforms enable resources to be shared and utilised easily within the work environment as well as in private life. These digital platforms further support the DIY (do-it-yourself) society whereby self-production of fashion, technological equipment and food become the standard as consumers request tailor-made solutions. A DIY society with strong customer awareness obliges multinationals to use a "glocal" approach. Global companies hence compete with local players by recognizing differences in local taste and customs. Accordingly, companies have the flexibility to respond to local customer needs in order to remain on regional and local markets. At the same time, those global companies adapt their product and service offerings to a growing number of markets.

Disruptive technologies develop within this stable political and economic environment and additional solutions spread rapidly. These technologies not only increase the degree of freedom in manufacturing processes but also allow more efficient and effective work processes. Coupled with the ability to share and act upon the associated data and derived insights, new service- and production related business opportunities arise, especially for start-ups. While focusing on niche markets and lean organisational structures, they handle high volumes of data flow efficiently. Emerging technologies such as advancements in AI assist humans by undertaking planning and handling tasks autonomously. Since many physical and intellectual tasks are increasingly taken over by technical developments in automation and economic empowerment, this has the knock-on effect of a decrease in demand for manual labour. With the increasing exploitation of these technologies, the environment becomes highly automated and autonomous. The resulting knowledge-based economy's labour market is characterised by cross-disciplinary, creative profiles and lifelong learning. Employers cope with the demand for flexibility and will adopt an intercultural model partly equalising the resulting labour overflow.

These newly efficient work processes contribute to reducing the overall energy required within the industrial sector. In addition, technological developments allow for renewable energy generation as well as transmission and distributed energy resource systems to become more prevalent. Most importantly, politics actively enforces ecological development and ensures environmental regulations are updated 
Table 2 Elements of the PrOCEEDIng scenario

IIII Political concord in EU; widespread free trade; stable alliances

US and EU as global trade leaders; digital platform economics; Bank and Fintech collaboration; global companies operate locally

i Social balance; adjusted labor market; strong consumption individualisation (DIY, variant diversity); living in smart cities

Digitalization and Industry 4.0 widely implemented; electrification and ecological transition far advanced; start-ups and SMEs push disruptive developments

§ Legislative keeps pace with technological development

Climate protection successful; resource wastage curbed

rapidly and early on. The PrOCEEDIng scenario contains the future projections mentioned in Table 2.

PrOCEEDIng-Effects on supply chain Global and multinational supply chains in the framework of this scenario have to adapt their supply chain structures towards a regionalised setting. Technological advancements and the legal frameworks allow for new, fast and responsive supply chains which are able to respond faster to changing customer needs. The advancements of digitisation allow for rapid recovery mechanisms in pandemic situations and enable a quick ramp up of supply chains, potentially with newly formed supply chain structures. Effects on structure and processes go hand in hand with requests for a circular economy and enforce circular product life cycle developments. From a process perspective, disruptive technologies support good and holistic planning via algorithms. The use of predictive analytics leads to better forecasts, improved efficiency and hence reduced or at least more predictive lead times. Therefore, the associated supply chain costs will decrease (e.g. through efficient risk management). Additionally, demand for highly individualised products involves flexible processes and equipment that are capable of handling a variety of products and material flows. 


\section{3 “oFFsET"-Free Trade Enables Political and Social Development Whereas Fragmentation Hinders Technological and Environmental Change}

\section{oFFsET-General settings}

The scenario settings within oFFsET embrace diverse developments and can be characterised by the following aspects:

- Ecological problems and scarcity of resources are intensifying

- EU continues to develop steadily in political and economic terms

- Spread of technological innovations is thwarted, partly because of inadequate legislative frameworks

In this scenario, the world has to deal with severe environmental problems. $\mathrm{CO}_{2}$ emissions are increasing around the world and there are major sources of greenhouse gas emissions. The most visible consequences include the continuous escalation of climate disasters and the increase in air, water and soil pollution. Climate change is combined with a severely ongoing depletion of resources for civil as well as industrial use; the ever-increasing global population and economic growth contribute detrimentally to the natural resources of our planet. Highly populated countries face severe issues related to water scarcity or complete lack of access to water. Climate change induces natural disasters and raises the frequency of pandemics, which in turn has a negative effect on the economy and reinforces social disparities. These environmental issues are reinforced by different factors from other future projections. A 'much and cheap' consumption attitude is adopted by consumers. Add to this the fact that the world is increasing the production of solid, hazardous and electronic waste. The recycling rate remains low and countermeasures to avoid high waste are implemented poorly, or, strong laws and policies for waste and recycling management are missing. The developments restrict any focus on environmental actions that support climate protection. Nevertheless, there are some ongoing countermeasures. They include, inter alia, the use of renewable energy resources and smart grid solutions that are promoted by better connectivity and efficiency in smart cities. At the same time, in the industrial sector, green systems are progressively applied for power generation, energy storage and transportation, such as hydrogen power cells and biomass. Standard mutual roadmaps and common policies are missing; for this reason, solutions for smart power grids develop more slowly than expected.

Political and economic uncertainties arise, which, inter alia, lead to ambiguous legislation, thus impeding the adoption of new services and important technological developments. It hinders the digital transformation of industries as the high cost of implementation, and reluctance towards new digital processes, slows down the redesign of processes. Only a few companies, mostly multinationals, overcome the legislative and regulatory constraints and implement the digital technologies that are available thus resulting in a coexistence of conventional and disruptive production technologies. Global players dominate while the big five IT companies (Google, 
Table 3 Elements of the scenario oFFsET

IIII. Constant development in EU; free trade; instable alliances

Asia drives economic development; global companies act local; techgiants dominate financial sector

- Social balance; adjusted labor market; "much-and-cheap" consumption influenced by social media; living in smart cities

Digital transformation is slowing down due to cost and retention; autonomous systems are only occasionally successful; coexistence of conventional systems; further efforts for electrification and alternative energies

§ Legislation falls behind technological development; heterogeneous regulations and low levels of trust in data privacy and market regulation

Climate protection targets are not achieved; strong pollution; scarcity of resources

Apple, Facebook, Amazon, Microsoft) offer their own financing system to facilitate seamless payments. Table 3 outlines the integrated future projections of this scenario.

\section{oFFSeT-Effects on supply chain}

The depletion of resources disrupts business continuity, particularly for manufacturing companies that try to reuse their products and improve their designs in order to reduce material and disposal costs. Hence, sustainability and scarcity issues call for changes in several areas of the supply chain. Some companies may also relocate their plants to access resources or avoid barriers posed by regulations. Environmental regulations are not homogeneous and a common sustainability agreement throughout the supply chain is needed, such as is intended by the EU Circular Economy Action Plan (European Commission, 2020).

From a process perspective, a few new technological advancements allow some processes to be simplified so supply chains can work smoothly with reduced costs, thus serving the 'much-and-cheap' society. In addition, the 'much-and-cheap' consumption pattern requires lean and efficient process settings to reduce the overall logistics costs. 


\section{4 “DiThEr"-There Is Digital and Technological development but not Enough to compete Globally}

\section{DiThEr-General setting}

The DiThEr scenario entails a mixed view on future developments and emphasizes technological innovations. This scenario is characterised by the following specifications:

- Continuous development and integration of new technologies, regardless of reluctance towards digitalisation

- Start-ups profit from technological developments

- Good acceptance of autonomous systems in the EU but this results in high unemployment and social imbalances

- Political environment changes towards protectionism

- Promotion of ecological and sustainable development of products.

In this scenario, the economic development in the EU benefits from the advances in technology, such as additive manufacturing, automation and the dynamic development of autonomous technology. These innovations make the production of individualised products with specific adjustments cost-effective, both for global players and SMEs. Companies try to postpone their production until the latest point possible to allow individual customisation, while the exploitation of disruptive production technologies promotes design-driven manufacturing processes and precise control in industry. These conditions promote the continuous exploitation of technologies and the fast development of autonomous technologies. Even though technology advances create new jobs, emerging skills are required and the re-employment of workers becomes difficult. In particular, robots and autonomisation take over manual and white-collar tasks: the unemployment rate increases and this contributes to social and political unrest. Pandemic outbreaks further enhance these developments and simultaneously trigger technological developments as well as business disruptions and social disparities.

Despite constant political development in the EU, across the globe, enclosed political environments lead to policies to protect domestic industries against foreign competition, entailing trade policies such as geographic barriers, tariffs, import quotas or other restrictions on imports from foreign competitors. These lead to complications in logistic structures, and some companies withdraw from the market. The EU is going into crisis and several countries are putting their own needs first and choosing to leave the union. This, though, in combination with the technology innovations, supports the establishment of DIY production. It particularly enables start-up companies to enter local market segments and introduce technological advancements. Such companies use new relations towards emerging economies, e.g. MINT countries (Mexico, Indonesia, Nigeria and Turkey). At the same time, stringent legal regulations, data management and privacy issues impede digital transformation. Digital transformation is advocated principally by multinationals who have the required financial resources to adopt the latest technological applications. Overall, the scenario 
Table 4 Elements of the DiThEr scenario

IIII Constant development in EU; closed economic areas; collapse of alliances

Asia drives economic development; global companies act local; digital platform economics; Bank and Fintech collaboration

i9 Aging society with large disparities and high unemployment; strong consumer individualisation (DIY, variant diversity), living in smart cities

Digitalization obstructed by cost and retention; increased use of autonomous technologies; electrification and ecological systems are well advanced; start-ups benefit from the evolving technology industry

§ Legislation falls behind technological development; heterogenous regulations and low levels of trust in data privacy and market regulation

Climate protection successful; resource wastage contained by technological developments

states mixed developments with strong support from technological advancements. This also enables sustainable and ecological production technologies that support development and climate protection.

Table 4 describes the future projections within the scenario DiThEr.

\section{DiThEr-Effects on supply chain}

Future supply chains in this scenario need to be resilient due to an unstable environment and challenges derived from protectionism. Economic developments are difficult to predict, which makes it necessary to build strong local supply chains with regional partnerships. Nevertheless, personalised production and further partnerships with DIY entities require end-to-end tracking along the supply chain that encourages further aspects of transparency and circular economy. This therefore opens up ways for resource re-utilisation. Pandemic disruptions and natural disasters have strong effects on the operation of supply chains and induce the use of autonomous processes. Advancements in autonomous technologies lead to changes at process level with a focus on new ways to automate non-added value activities in the supply chain. Companies and politics need to consider that technological changes can cause unemployment; hence, strategies to reallocate staff along the supply chain need to be defined. This becomes even more important as disruptive changes create new production and service processes. 


\section{5 “UNEaSE"-UNstable political sEtting and power Shifts hinder technological and Environmental development}

\section{UNEaSE-General setting}

UNEaSE provides a scenario with a mixed setting heading towards retrogressive development that includes the following main aspects:

- Growing political and economic uncertainty due to collapsing alliances, high unemployment and increasing social disparities

- Megacities and the economic focus on BRICS \& MINT prohibit ecologically balanced development

- Outdated legislation as well as restricted digitalisation and limited technological developments cause traditional development of the economy.

The 'UNEasE' scenario comprises growing political and economic instability in the EU. The lack of stability helps BRICS and MINT countries to develop and become significant economic players with China playing a significant leading role. Besides, Chinese investments on economy and export markets further help China to overtake Europe as the world's net investor. Relations between countries become increasingly tough. Several trade relations suffer due to the political developments and lead to trade issues, which could potentially lead to trade wars. At the same time, increased protectionism as well as local and individualistic consumption patterns incentivise start-ups and SMEs. This, combined with the fact that society strives to promote DIY characteristics, enables small businesses to flourish. However, the rise of SMEs and start-ups leads to legal and political concerns due to the innate characteristic of dynamic markets created by the introduction of new business models. The political instability within the EU hinders legislative developments, however, and increases the development of heterogeneous regulations.

The focus on emerging countries leads to concern about legislation within increasingly dynamic markets, including a lack of heterogeneous environmental regulations, and low confidentiality of data and market participants. Lagging legislation also affects regulations and consumer protection laws in the EU. The lack of liability regulations in case of infringements mean core data and business secrets can be exposed. Challenges of data ownership and data management must be addressed in order to make use of the business potential inherent in digital transformation endeavours, which are often faced with lack of acceptance on the part of consumers, due to privacy or data security concerns. Only a few multinational companies are able to improve their performance through digital transformation, since only they can cope with the high costs and risks it involves.

The shift of economic dominance to emerging markets, combined with such heterogeneous regulations, sees economic priorities being placed before ecological ones, which in turn supports a steady increase in natural resources depletion. Highly populated countries face severe issues related to water and resource scarcity. A constant development towards megacities and the focus on emerging countries contribute to negative environmental impacts such as depletion of natural resources 
Table 5 Elements of the UNEaSE scenario

IIII. Constant development in EU; protectionism; collapse of alliances

A Asia, BRICS \& MINT drive economic development; global companies act local; Bank and Fintech collaboration

Aging society with large disparities and high unemployment; strong consumer individualisation (DIY, variant diversity); living in smart cities

Digitalization obstructed by cost and retention; autonomous systems hardly prevail; further efforts for electrification and alternative energy sources; start-ups benefit from advancing technological development; coexistence of conventional and disruptive technologies

8 Legislation falls behind technological development; heterogeneous regulations and low levels of trust in data privacy

Climate protection targets are not achieved; strong pollution and scarcity of resources

and atmospheric pollution. These environmental developments support pandemic outbreaks and lead to political denunciations. This further promotes the trade issues mentioned above and increases the probability of trade wars. Table 5 describes the future projections inherent in the UNEaSE scenario.

\section{UNEaSE-Effects on supply chain}

In terms of supply chain structure and resources, the growing uncertainty and political instability in the EU as well as the shift of economic power to emerging markets leads companies to rethink their supply chains. Due to barriers to the free flow of goods, disruption to supply chains increase with longer waiting times at border crossings. As companies experience contracting markets and escalating logistics costs, they move to strategies such as right-shoring, which is the combination of on-shoring, nearshoring and far-shoring. Supplier location will play a crucial role in minimising costs, accessing resources and minimising environmental impacts. Firms that had identified low cost Asian suppliers experience a rise in labour costs, however, accessibility to resources such as rare earth elements makes these suppliers non-substitutable.

The slow adoption of new technologies impedes digital transformation. Thus, the traditional exchange of data dominates supply chain processes that restrain further network developments. For supply chains, SMEs and start-ups such as Fintech act as intermediaries in facilitating transactions and facilitate both the supplier and the contracting company to improve their working capital, which means greater liquidity in scheduling and disbursing payments. 


\section{6 “ENDANGEr”-EuropeaN Disintegration and Protectionism lead to Geopolitical, Social, Environmental, Legal, Technological and Economic Issues that Affect Company's Success}

\section{ENDANGEr-General setting}

The ENDANGEr scenario displays a regressive future. Instability hinders future growth especially in terms of technological development. The following aspects summarize the features of this scenario:

Political instability and the collapse of the EU lead to the isolation of the former members

- Autonomous systems lead to high unemployment

- High social inequality and consumption of mass-market products

- Direct financial system with ledgering supports traditional goods exchange

- Little to no social development.

ENDANGEr describes an unstable political environment that causes social and economic issues. This incorporates a change in trade and hence a shift of gross domestic product from advanced economies towards emerging market economies. Political instability leads to stagnating and non-homogeneous legislation limiting the development of emerging technologies. Moreover, only a few big companies can take a leading role in managing and processing high volumes of data; thus, there are obstacles to achieving smooth digital transformation. In the financial sector, however, smart contracting with distributed ledgers enables customers' transactions to be carried out without any intermediary; hence, classic banking services are becoming obsolete. Instead, cryptocurrencies support the traditional exchange of goods.

Companies adapt their business structures with autonomous technologies and processes. In the EU, manual tasks are taken over by technical developments such as automatisation, which makes reemployment more difficult as it demands skilled workers. Since whole industries are affected by autonomisation, the overall rate of unemployment rises. Automated and partly autonomous factories are progressively becoming the standard in EU. This contributes to employees fearing for their jobs, eventually adopting a negative attitude towards emerging advanced technologies. Since complete industrial sectors are affected by automatisation, there is an increase in income disparities. Despite all efforts, high associated costs and unclear regulations hinder the proliferation of e-mobility, particularly in rural areas. Ambiguous regulations hinder common ecological agreements and as policy neglects environmental issues, pollution and the scarcity of resources increases. Table 6 states the different future projections, most of them regressive, for the scenario of ENDANGEr.

\section{ENDANGEr-Effects on supply chain}

The instability and stagnating development in this scenario affect supply chains in both their structures and processes as well as the supporting infrastructure that acts as an enabler for supply chains. Constrained public investment in logistic hubs, 
Table 6 Elements of the ENDANGEr scenario

IIII Political instability in EU; protectionism; collapse of alliances

Asia drives economic development; global companies act local; political instability leads to a traditional goods exchange based on crypto-currency

Strong social inequality especially; aging society with high

unemployment forces to consumption of cheap mass-market products; living in smart cities

Digitalization obstructed by cost and retention; increased use of autonomous technologies; e-mobility and alternative energy sources benefit from previous research; dominance of multinationals inhibits further development of new technologies

$\S$ Outdated, inhomogeneous legislation; low data privacy

No ecological agreements; heavy pollution; scarcity of resources

e.g. ports, means last mile and rural deliveries are frequently delayed. In addition, the fragmented market causes a shift towards local supply chains. This leads to raised costs due to the duplication of processes and inventories for each local supply chain. New local distributional and production hubs need to be set up and several new supplier partnerships have to be formed. The duplication of assets across the European region results in inefficiencies, and new barriers and taxes are expected. As the political and economic situation is instable, it affects the resilience of both global and local supply chains. Depending on how 'a world without banks' is set up, where financial processes are handled from individual to individual by means of an independent cryptocurrency, there might be an impact on payment processes.

The changes to supply chain processes lead to a rise in the complexity of managing processes and resources. The scenario settings here induce more bureaucracy and movements of goods become slower as handling steps are duplicated. Future economic developments require re-organisation as international supply chains face difficulties in maintaining relationships with suppliers. Accordingly, access to resources and commodities are affected and resource scarcity remains an issue. A fast development of autonomous systems provides a solution to efficient process design in distribution. As customers focus on cheap products, lean processes dominate as they can achieve corresponding cost reductions. New business models are required to handle the steering of autonomous systems and the increasing complexity within local markets. The setup of fragmented, local markets reduces possibilities for economies of scale and thus decreases efficiency. This is partly balanced out 
as economic and political developments create additional market barriers, which diminishes competition.

\section{Conclusion}

This chapter describes six macro-scenarios that provide settings for how future supply chains could be by 2030 . The scenarios were developed by methodologically bundling relevant trends and experts then evaluated and discussed their content. Each macro-scenario contains an overview of the general scenario settings and then draws conclusions for its impact on supply chain structures and processes. Considering the generation of scenarios, it is of importance to highlight scenario descriptions as conceptual frameworks, which include progressive as well as stagnating or regressing views of the future. Accordingly, the interpretation of the impact on supply chains provides differentiated views of future developments. The scenario descriptions in this chapter enable companies to evaluate different scenario settings and to appraise the respective consequences. Companies, and their supply chain managers in particular, can use this to prepare themselves for upcoming strategic challenges.

Acknowledgements The development of the macro-scenarios and their revision have been supported by the members of the EU project NextNet. In this respect, special thanks for their continuous support and advice go to Aristides Matopoulos (Aston), Mustafa Çagri Gürbüz (ZLC), Carolina Cipres (ZLC), Irene Marchiori (STIIMA-CNR), Pedro Pinho Senna (INESC TEC), Sebastien Balech (PNO).

\section{References}

Amer M, Daim TU, Jetter A (2013) A review of scenario planning. Futures 46:23-40

European Commission (2020) EU circular economy action plan: a new circular economy action plan for a cleaner and more competitive Europe. https://ec.europa.eu/environment/circular-eco nomy/index_en.htm

Meinert S (2014) Field manuel: scenario building

Sardesai S, Stute M, Kamphues J (2020) A methodology for future scenario planning. In: Fornasiero et al (eds) Next generation supply chains: a roadmap for research and innovation, Springer, Berlin

Wilkinson A, Eidinow E (2008) Evolving practices in environmental scenarios: a new scenario typology. Environmental Research Letters (3) 
Open Access This chapter is licensed under the terms of the Creative Commons Attribution 4.0 International License (http://creativecommons.org/licenses/by/4.0/), which permits use, sharing, adaptation, distribution and reproduction in any medium or format, as long as you give appropriate credit to the original author(s) and the source, provide a link to the Creative Commons license and indicate if changes were made.

The images or other third party material in this chapter are included in the chapter's Creative Commons license, unless indicated otherwise in a credit line to the material. If material is not included in the chapter's Creative Commons license and your intended use is not permitted by statutory regulation or exceeds the permitted use, you will need to obtain permission directly from the copyright holder.

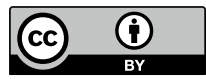

